\title{
Elementary school pupils' co-inventions: products and pupils' reflections on processes
}

\author{
Stiina Sinervo ${ }^{1} \cdot$ Kati Sormunen $^{1} \cdot$ Kaiju Kangas $^{1} \cdot$ Kai Hakkarainen $^{1} \cdot$ Jari Lavonen $^{1}$. \\ Kalle Juuti ${ }^{1}$. Tiina Korhonen ${ }^{1}$. Pirita Seitamaa-Hakkarainen ${ }^{1}$
}

Accepted: 9 March 2020 / Published online: 18 March 2020

(c) The Author(s) 2020

\begin{abstract}
The study focuses on examining elementary pupils' ( $\mathrm{N}=42,11-13$ years old) reflections on collaborative design processes, team collaboration and their co-inventions. Digital and traditional fabrication technologies were used in a 2-year co-invention project containing approximately 16 sessions during year 1 and 11 sessions in year 2. Between the two project periods, the pupils were asked to write a structured essay about their co-invention and design process, and in year 2 they kept journal notes in each team's design-folder. Each pupil's structured essay was analyzed with qualitative content analysis that focused on three main aspects: (1) description of the co-invention, (2) progress of the co-invention process and (3) quality of collaboration. Based on the essay analysis, we constructed a "Co-invention Table" with five categories: user, conceptual design, technical design, appearance, and construction. The nature of the 13 pupil-teams' co-inventions varied greatly, and these coinventions were divided according to three main functions: (1) improving cleanliness, (2) providing reminders or (3) addressing well-being. The essays provided information on how creative ideas were generated and how critical thinking and evaluation of ideas were crucial in improving ideas for further development. The collaboration was dependent on everyone's active and equal participation into work and the importance of an adequate division of the labor was highlighted.
\end{abstract}

Keywords Co-invention $\cdot$ Design process $\cdot$ Critical thinking $\cdot$ Collaboration

\section{Introduction}

In order to cope, in the future, with formidable, ecological, social, and economic problems, pupils need to learn to use knowledge creatively, to make innovations. Although the Finnish National Curriculum prescribes that pupils' innovativeness is to be fostered at school (Finnish National Agency of Education 2016; Howard et al. 2008; Rutland and Barlex 2008), pupils seldom have opportunities to engage in collaborative design processes and in designing technology inventions as solutions for concrete everyday-life challenges. To

Pirita Seitamaa-Hakkarainen

pirita.seitamaa-hakkarainen@helsinki.fi

1 University of Helsinki, Helsinki, Finland 
better understand the ways to scaffold pupil learning of such future competences, we examine the nature of the Finnish mixed-ability pupil teams' co-inventions in grade 5 and 6 and their reflections of the 2-year innovation processes.

In an invention process, one is designing and combining ideas and knowledge he or she already knows to create something new (Howard et al. 2008) whereas co-invention is an invention that is created jointly by two or more people. Thus, co-invention can be seen as a collaborative, iterative design process of applying knowledge and skills for making novel and practical solutions intended to fulfill relevant real-world needs and solve associated problems (Honey and Kanter 2013, p. 3; Rutland and Barlex 2008). The collaborative outcome of the process, a co-invention, can be defined as a novel, appropriate solution and valuable response to an open-ended task solved by several participants together (Denson et al. 2015). The widely recognized definition of innovation embraces concepts such as originality, promisingness and appropriateness (Bereiter and Scardamalia 1993; Howard et al. 2008). Inventions are sometimes understood to be technological and solve a technical problem whereas the innovation can also be a substantially improved, economically useful product, process or service. When pupils are engaged in the co-invention processes, they are learning to identify users' needs, seek and frame problems, explore solutions, ponder alternatives, communicate their ideas verbally, visually, and materially, and collaborate (Davis et al. 1997; Kangas et al. 2013; Yrjönsuuri et al. 2019). Nevertheless, the educators must understand the meaning of co-invention project in order to scaffold, encourage, and guide pupils' inventive outcomes during the collaborative design process.

In order to understand better what kind of support pupils' might need in their co-invention projects, we analyzed pupil teams' co-inventions and their reflections about the highly open-ended co-invention project. Designing requires creative thinking: defining the design task, generating and creating conceptual and visual (physical) design ideas. It also requires critical thinking: evaluating design ideas and design constraints as well as evaluating and experimenting with ideas and prototypes (Seitamaa-Hakkarainen et al. 2010). In the present article, we will describe and analyze pupils' reflections on the overall process of the co-invention project by examining the pupils' co-inventions made in collaborative groups. We are interested in what pupils think and remember about the project. The analysis also sheds light on what has been important to them and reflects on their design learning during the project. We address the following specific research questions:

(1) What kind of functionalities and attributes did the teams' co-invention consist of, and how do pupils characterize the properties of their co-invention? What kind of underlying values and motivations were related to co-invention?

(2) How did pupils describe and reflect their co-invention processes?

(3) How did they describe and reflect their team collaboration? What were the major difficulties pupils encountered in an open-ended co-invention process?

\section{The co-invention process as knowledge-creating learning}

We see pupils' co-invention process being an archetypical form of knowledge-creating learning (Kangas et al. 2013), where one has to learn not only what is already known, but also go beyond what is given and learn the potentials in a situation for creating something new. Similar to knowledge-creating learning, the co-invention process emphasizes materially embodied, making processes (cf. Kangas et al. 2013; Yrjönsuuri et al. 2019). Accordingly, facilitation of the co-invention process in learning requires engaging pupils 
in solving complex open-ended problems and focusing explorations on parallel work with ideas and implement, experiment with these ideas by creating materially embodied artefacts; being, simultaneously, both "hands-on"' and "'minds-on".

The explorations with materials and tools are pivotal aspects of learning by making. Pupils' engagement is related to motivating, open-ended design task that provide encouragements for various kinds of ideas and designs. Pupils' inventions are actualizations of maker-centered learning (Clapp et al. 2016). In maker-centered learning, participants are not only building conceptual knowledge but also creating new artifacts and cultivating new ways of thinking and acting (Blikstein 2013; Kafai 2006; Kafai et al. 2009; Papert 1991). In maker-centered activities, pupils engage not only to design learning but also to scientific and engineering practices and collaboration with other students (Martinez and Stager 2013). This type of learning is considered to be beneficial and engaging to all pupils learning (Alper 2013; Martinez and Stager 2013). In a collaborative invention process, design ideas are iteratively evaluated and refined, gradually transformed in various material forms; that there is increased specificity of the proposed product ideas (Kangas et al. 2013).

Blikstein (2013) emphasizes that maker-centered learning gives affordances in enriching science, technology, engineering, arts and mathematics (STEAM) studies. In Finland, craft education has been an important part of basic education. The goal of the subject is to identify problems and needs, to consider options and design constraints, plan, model, test and iterate solutions. It is seen as exploratory, inventive and experimental activity. The Finnish curriculum puts emphasis on multi-materiality and development of versatile, working capabilities (Finnish National Agency of Education 2016). Further, the curriculum of craft education highlights collaboration, multimodality, documentation and digitalization. Collaboration refers to an situation in which pupils actively communicate and work together in the design process, identifying constraints, creating and sharing ideas, deliberately making joint decisions and producing shared objects, constructing and modifying their design solutions, as well as critically evaluating their outcomes through discourse (Hennessy and Murphy 1999; Seitamaa-Hakkarainen and Hakkarainen 2017).

\section{Frameworks for evaluating innovative design concepts}

In design and technology education, pupils' design challenges are most often to solve technical problems or "engineering" problems, and thus the evaluation criteria also tend to emphasize the technical attributes of the device or product. For example, Gero and Kannengiesser (2004) have proposed a framework for engineering design that is based on the three aspects of a design product: Function, Behavior and Structure. A function is the purpose a thing serves, related to the problem. A behavior consists of the way the object interacts with its environment. Structure, in turn, involves the physical shape or holistic outlook of the object. These three aspects reveal what the product is for (function), what it does (behavior), and what it is (structure), and these come close to the criteria that in engineering are required for an invention or a patentable design.

Evaluating the innovativeness of pupils' production, however, is challenging since the solutions often will vary widely due to many factors and to the fact that design tasks are usually open-ended. In design and technology contexts, novelty and appropriateness of outputs are assessed in relation to the design brief or problem. Products must be relevant, that is, meet the task requirements. These products should also be effective; specifically, they must be capable of fulfilling some practical purpose. Regarding technical solutions, the phrase 'fitness for purpose' refers to how such a solution supports its 
intended function. Further, not all outputs of a design task meet the task requirements; they might be novel but not relevant. In such contexts, investigators have applied the concept of 'quasi-creativity' (Cropley and Cropley 2010) to products that share many of the same qualities as genuine creative products without, however, providing an actual solution.

Barlex (2007) argued that the most important part of design and technology education is to assess the pupils' design processes through which they can demonstrate designerly behavior by making proper decisions. In solving authentic and open-ended design tasks, pupils are required to make decisions that are related to conceptual as well as technical design. They make decisions about the way their design will work. In order to support pupils' designerly thinking, Barlex (2007) has proposed a framework for scaffolding pupils' decisions through revealing and justifying their design decisions. Barlex's (2007) approach is based on a pentagon of five domains of design decisionmaking. Accordingly, each type of design decision is located at a corner of a pentagon. The areas concerning conceptual, technical, aesthetic, constructional and marketing aspects of a design product are interlinked so that making decisions within one area may change the others as well (Barlex 2007). The pentagon describes the features or attributes that pupils intend their product to have (see Fig. 1).

However, Derboven et al. (2015) have argued that a descriptive analysis of children's design ideas or decisions is not enough, and the focus should be shifted from functionalities and attributes toward the underlying motives and values behind design decisions. According to Derboven et al. (2015), the multi-modal analysis of pupils' innovative concepts that both integrate the material dimensions (tangible material outcomes) of codesign artifacts as well as their verbal explanations would provide much more detailed descriptions for the underlining values of co-design outcomes. Thus, situating co-design outcomes in its origins can clarify why particular (design) decisions were made and by comparing the original ideas and the results, it is possible to trace how ideas emerged and evolved throughout co-invention project.

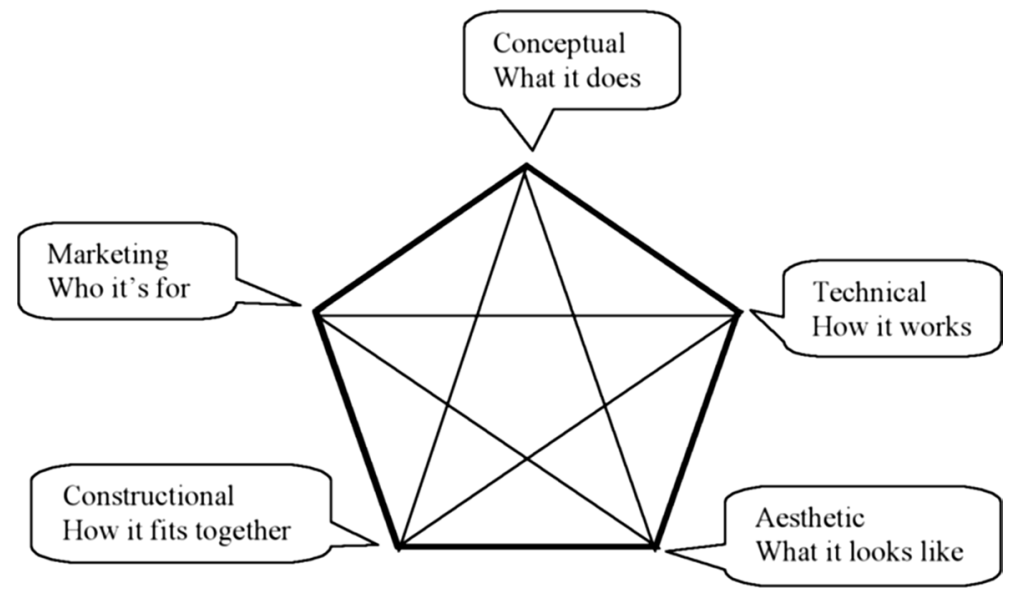

Fig. 1 The design-decision pentagon (Barlex 2007) 


\section{Research methods}

\section{Context and participants}

The co-invention project was organized in two project periods in spring 2016 and spring 2017 in an elementary school in the capital area of Helsinki, Finland. The pupils were involved in design projects two consecutive years, and in spring 2017, the class was in their final year in primary school (6th grade), and after that, they continued in middle school. The school followed inclusive education and innovation pedagogy, and on average, one out of every six pupils in the school had identified learning difficulties (LD) and a guarantee for special education teacher's support. In Finnish education practices, the need for special education support is related to LD that are often described as problems in language (reading, writing, speaking, listening), mathematics, attention and action control, perception, and fine or gross motor skills. These difficulties might negatively affect pupils' self-esteem and their overall sense of wellbeing (Niilo Mäki Instituutti 2015). In the beginning of the research period, altogether 42 th graders, aged 11-12 years participated in the co-invention project. Ten of the pupils had identified LD (two girls, eight boys). The participating class had two classroom-teachers (master degrees) and one special education teacher (master degree). Teachers had experience in developing invention pedagogy, but they had not specialized craft and technology education. Informed consent of teachers, pupils and parents were collected following the ethical principles of the University.

All teachers had extensive experience as elementary school teachers, and they had been working together as a team for several years. Teachers and researchers participated in shared planning sessions at the faculty campus and school: The plan for the co-invention unit emerged through collaboration between the researchers and teachers. However, the teachers were in charge of designing and enacting the co-invention project units in their class. During the first period (spring 2016) the general phases were planned together (for example visits and visitors) as well as the unit for a visit to entrepreneurial village (fall 2016), however, conducting the second period was based on the teachers own requests to continue with the co-inventions. In the first year, one of the researchers was present by collecting video data of three teams' working, but during the second period, she took a more active role by participating on projects, especially helping the teachers and pupils with digital technology. In other words, the research design was not strictly preplanned as certain kind of longitudinal studies (two periods); rather it was formulated upon a given situation.

\section{The co-invention project unit}

At the beginning of the project unit, pupils were asked to analyze their daily activities as well as the products, tools or gadgets they use on an everyday basis. The invention challenge was to create a co-invention that makes everyday life easier. The co-invention challenge was to "Design an intellectually challenging, aesthetically appealing, and personally meaningful, complex artifact making daily activities easier. It could be a new or improved invention, and it should integrate material and digital elements."

The project lasted for approximately 16 sessions during spring 2016 and about 11 sessions in spring 2017 (Table 1). For the co-invention project unit, there were allocated about 2-3 lessons once a week. During the project, the pupils worked in teams, including 2-5 pupils. In the middle of the first period, teams presented their ideas and plans to the whole 


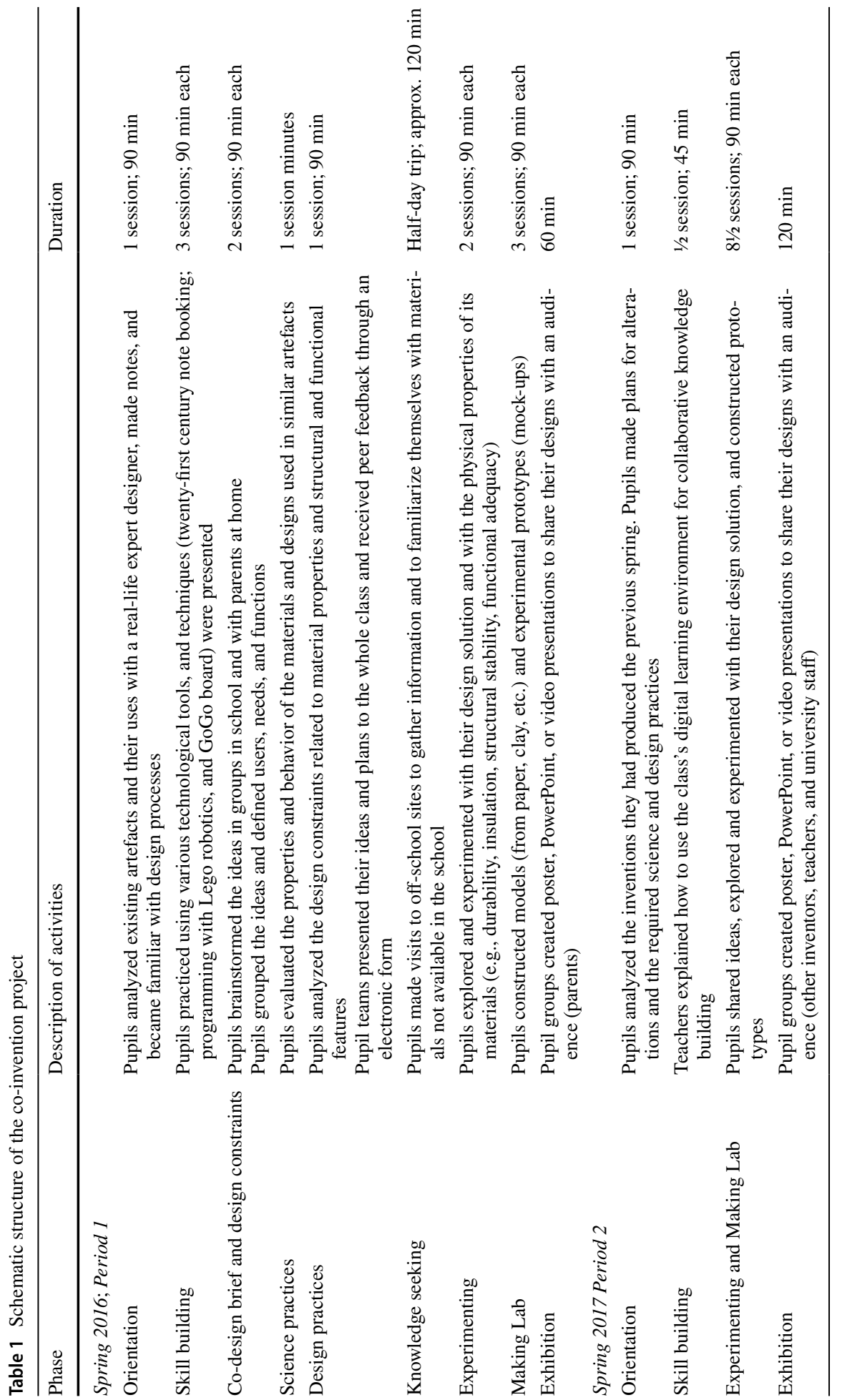


class and received peer feedback through an electronic form. At the end of the first period, the groups created a poster, PowerPoint, or video presentation to share their designs with parents and in the final year, they shared their designs with a broader audience in the Invention Fair. Between the two study periods in fall 2016, pupils had a site visit emphasizing the entrepreneurial aspects of the invention project, but they did not develop their co-invention further at that time. The prime ideation and first (low-tech) prototype of the co-invention was made during spring 2016, and in spring 2017 the pupils concentrated on developing the prototype further or making the final product as well as making a poster presentation in the exhibition of Invention Fair. Table 1 presents an overview of the teacher-planned schematic structure of the main phases of co-invention project unit. The phases are described in general terms of unit plan, but during the project, the teams worked according to their own design process phases.

\section{Data collection}

The data was collected from pupils' design journal entries, structured essays, and three team's video recordings of design sessions and pupils' stimulated interviews at the end of the project. In addition, the researcher made notes during meetings with teachers and took photos during the project sessions to get an overall picture of all team's processes. When the co-invention project started in March 2016, pupils were asked to keep an individual diary on a paper notebook or a word document about their co-inventions. The aim was to follow all teams' visions of co-invention process through these design journal entries. The teachers demanded the journal entries but did not systematically monitor the quality of the entries and, thus, it was challenging for the teachers to follow entries that were documented on paper notebooks. In the first project period, journal entries consisted of brief lists stating what has been done in each session.

Since the pupils' journal entries were quite weak in the first year, the teachers asked pupil teams to document their project work digitally and more systemically and regularly in spring 2017. The pupil teams kept their team-based, structured, design folders; these consisted of written and drawn design-journal entries including photos that were to be worked on each time they had a co-invention session. The instructions for written designjournal entries were familiar to the whole team, but usually, one member assumed responsibility of writing it. For writing team-journal notes, writing prompts were provided: Pupils were asked to report what was done during the design session and to describe the division of labor, i.e., who did what. They were also asked to describe how the work proceeded and reflect on the nature of their collaboration during the design and making process. Further, they were asked to take photos and add the photos to the design folder. This time the teachers also monitored the documentation and gave some feedback to their design-journal entries.

To get a better picture of pupils project work and their reflections about the development of the co-inventions every pupil wrote a structured co-invention project essay in the middle of the project periods in the beginning of fall 2016. Pupils were asked to summarize their design process, to describe the nature of their co-invention and to evaluate team collaboration. Essay writing was facilitated by providing four, open questions, where pupils were asked to describe co-invention as much detail as possible. The instructions included the adapted version of Barlex's (2007) model consisting the following aspects of the coinvention: need for (i.e., why is it needed?), use or function (what is it used for?); technical (how does it work?), appearance (how does it look?), structure (what parts does it consist 
of, and how do the parts fit in?) and user (who is it designed for?). These questions helped pupils to describe and reflect on how the co-invention had progressed.

Furthermore, we video-recorded three teams' design sessions in spring 2016 and spring 2017. The general aim was to get a more detailed insight of some teams' processes, which could not be accomplished through observation. The three teams were randomly selected because we were not able to video them all. We also conducted individual stimulated recall interviews to the pupils in the videoed teams showing some of the photos or snapshots from the team projects folders in the end of the entire project in May 2017. We also viewed the pupil teams' presentations (video, Powerpoint etc.) presented in the exhibitions as well as peer feedback as additional material.

To conclude, it is evident that the young pupils do not remember all the design and making phases in detail level- especially when the design process extended almost 2 years. However, they were able to remember the main decisions they made during the project as well as reflect on their collaboration. Even we focused our analysis on the structured written essays we were able to cross-reference and verify the essay data toward other collected data (journal entries, team video data and pupils' interviews, researcher's notes and photos) by combining and comparing different data sets.

\section{Method of data analysis}

The data analysis was conducted in two levels: the qualitative content analysis of the pupils' reflective essays and the application of multi-modal analysis of the intended values and motives of the co-invention (Derboven et al. 2015). First, we performed a low-level analysis of functionality and attributes of the co-invention from the essay texts and prototypes (material presentation) or final products. Each pupil's structured essay was analyzed with qualitative content analysis. Altogether 42 pupils' written productions were analyzed using theory- and data-driven qualitative content analysis (Chi 1997), which was conducted by using ATLAS.ti qualitative content analysis program. The length, as well as the quality of the essays varied greatly. The analysis involved giving the data multiple readings and searching for patterns in the data. The analysis of the essays focused on three main aspects (1) description of the co-invention, (2) the progress of the co-invention process, and (3) quality of collaboration. Answering all prompted question was infrequent across all the teams, yet some of the group members had usually written more extensively about their coinvention process so that the overall co-invention was easier to reconstruct.

Before the actual, qualitative content analysis with ATLAS.ti, all team members' descriptions of the co-invention were read. Each co-invention was linked to two to five pupils' written essays across all the 13 co-inventions of the pupil teams. Thus, the first analysis focused on the children's writings about their co-invention that is the functionalities and attributes of the co-invention. After analyzing the pupils' written descriptions, we filled in the "Co-invention table" (Table 2) that listed the different attributes of the coinvention. The table consisted of five categories: user, conceptual design, technical design, appearance and construction. In addition, design journal entries from spring 2016 and spring 2017 were used to validate the analysis.

The teams were in different phases of their design processes when writing essays in fall 2016; consequently, all teams' design-folders (written journal notes, photos, presentations) made in spring 2017 were read through in order to supplement the data analysis. These diaries notes were used to complement the description of the teams' co-invention and the previous analysis. For the underlying values and motivation for the co-invention, we identified 


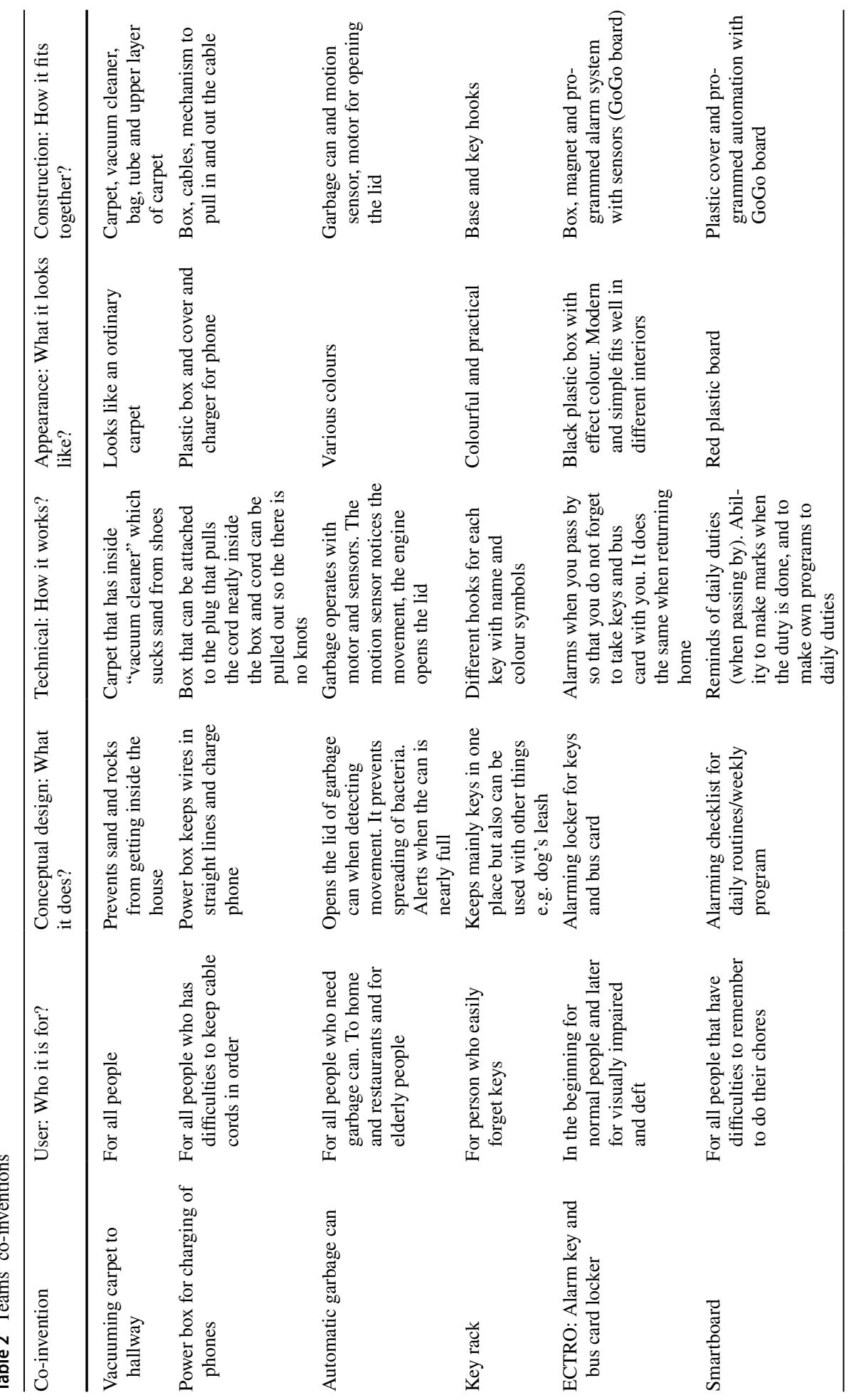




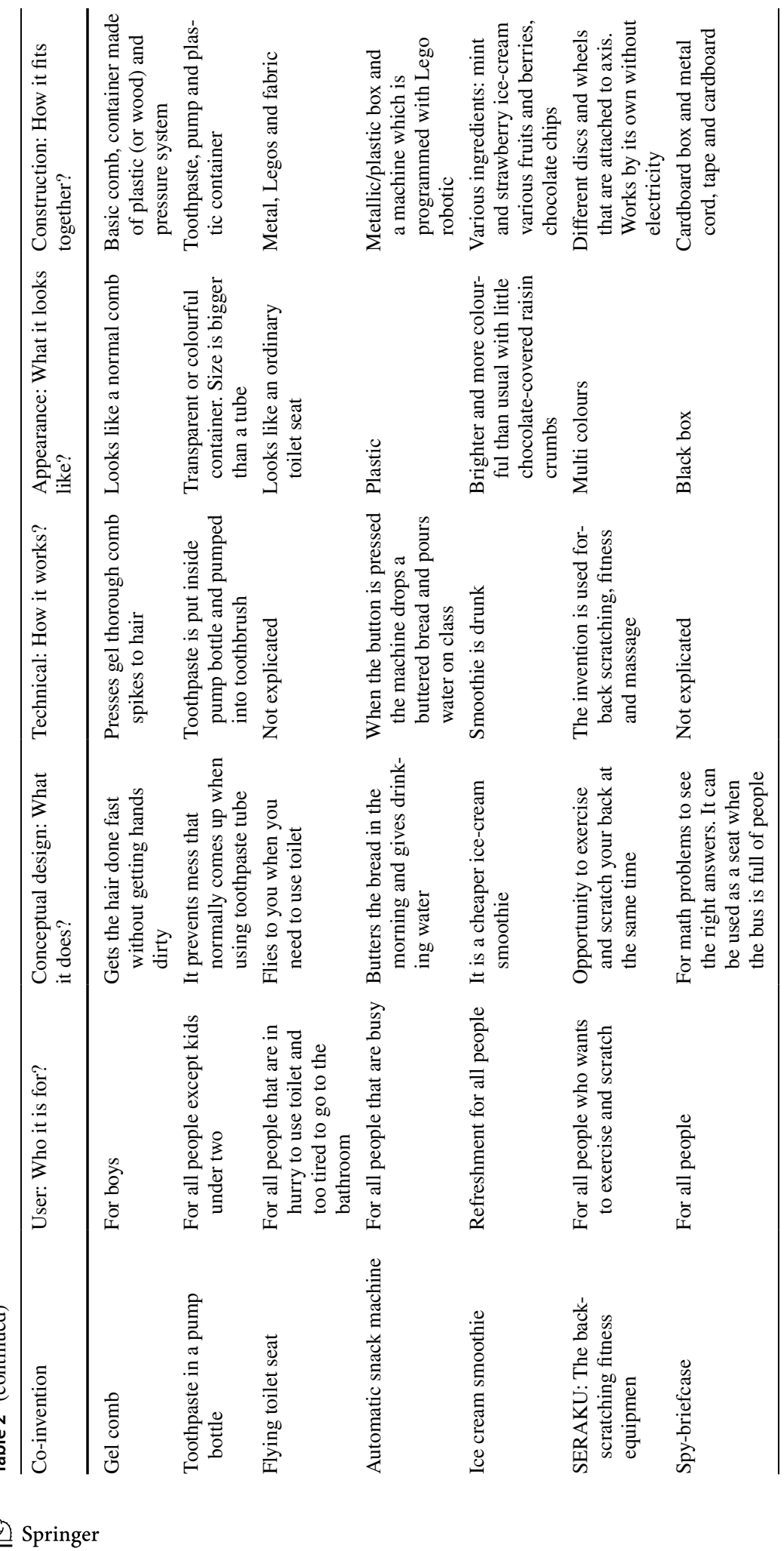


some themes from the essays that were related to explication of the user or specific use situation. These themes included aspects such as personalization (design can be modified according to someone's own preferences), or design will be modified according to special needs, i.e. support inclusion or health inequalities. In addition, some environmental aspects were found.

For the second phase of analysis, we analyzed all written-essay data concerning pupils' descriptions of the entire process by identifying instances where they explained various aspects of their co-invention processes. Main idea was selected as a unit of analysis. It varied from ideas expressed in one or two words to those of several sentences (Chi 1997). The progress of co-invention process was classified according to three main phases (see Seitamaa-Hakkarainen et al. 2010): (1) Refining design context, constraints and creating design ideas, (2) Evaluating design ideas and constraints, (3) Experimenting and testing ideas or prototype. The category of refining design context, constraints, and creating design ideas consisted of the notions about the given task, the teams' proposed initial ideas and design constraints, such as time, functionality, and implementation. The category of Evaluating design ideas and constraints consisted mainly of pupils' reflections on how ideas were selected and revised. The category of Experimenting and testing ideas or prototype categorized aspects related to building the prototype: pupils described how they built the prototype and how they tested it and described what they needed to change.

The final analysis of the co-invention project focused on (3) quality of collaboration because we were particularly interested in how pupils evaluated their interaction and working in teams. We looked at whether the pupils referred in their essays to "we" or "team" (i.e., the group has worked together) or whether the writer used only the "I" form in his or her writing. In addition, the team's collaboration was considered to be related to participation, division of labor as well as way of communicating. Similar issues were investigated from the interview data of videoed team members and compared with the all gathered data.

\section{Results}

In the following, we first provide a description of the teams' co-inventions by answering the first research question: What kind of functionalities and attributes did the teams' coinvention consist of and how do pupils characterize the properties of their co-invention? What kind of underlying values and motivations were related to co-invention? Then we will focus on the second research question of the nature of the pupil team's reflections of co-invention processes and quality of collaboration by examining how the pupils described their collaborative design process. Finally, we conclude to the third research question: What are the major difficulties pupils encounter in an open-ended co-invention process?

\section{The nature of pupils' co-inventions}

The given design challenge was very broad and included only one requirement: "It could be a new or improved invention, and it should integrate material and digital (e.g. circuits or robotic) elements." The 13 pupil teams came up with a wide variety of co-inventions. Although the design task highlighted the integration of digital elements, not all teams considered digital solutions applicable to their inventions. Only three teams proposed digital devices (such as processors or sensors) for their final designs. 
The user of the co-invention and the need for it usually appeared in the same analysis unit. In many structured essays, pupils (in the excerpts "S20" refers to pupil number) answered the question for whom the co-invention is intended in a form that also stated who will need the present co-invention, and what uses it will have.

Our product is designed for anyone who has problems with phone chargers to hold it straight or who just want to keep the wires neatly so that they are not visible. (S20)

It is used by people who are either going to school or going to work and don't have time to cook or want to have a quick drink. (S27)

The smartboard is for those who do not remember doing household work. (S9)

Following written descriptions of co-inventions were formed on the basis of the pupils' essays and co-invention table (Table 2). Some of the co-inventions changed considerably, for example, regarding their technical implementation. In the essays from fall 2016, the pupils' descriptions of the materials needed for the co-invention were mainly related to materials used in the prototypes and thus, it was possible that different materials were used in the prototypes of spring 2017. The pupil teams' co-inventions can be divided according to three main functions: (1) improving cleanliness, (2) providing reminders or (3) addressing well-being (hygiene, health and nutrition issues).

\section{Cleanliness co-inventions}

Vacuuming carpet was intended to work as a sand diver that sucks the sand from the shoes and prevents sand and rocks from getting inside the house. Preventing sand from entering home was first proposed to be solved by adding a thin membrane on the bottom of the shoes, then transforming the idea toward vacuuming power inside the carpet. The co-invention was envisioned as constructed of a base, vacuum cleaner, bag, tube, and top that looks like an ordinary carpet. In spring 2017, the final prototype of the co-invention did not have a vacuuming feature. The design solution had holes in the top part from which the sand fell into the base below the carpet.

The power supply box was designed to help to keep the home clean but also improve chargers' usability, that is, to keep phone wires straight. It was a plastic box with a mechanism inside it similar to the vacuum cleaner, which pulls the wires back in the box when the button is pressed. In the final prototype at the end of the project, the power supply box had a stand for the phone, and on the side, there was a lever that can be turned so that the wire could be rolled inside. The final prototype of the automatic garbage can operated with the motor and the movement sensor. The sensor detected movement at which point the engine opened the lid of the trash can without having to touch it and mess up one's hands. Figure 2 presents the final co-inventions related to cleanliness.

These three co-inventions were based on their use value: in all of these inventions the motivation for the product came from the identification of problematic use situations (preventing sand coming home, keep phone wires straight, open the lid of the garbage can) and the intended co-invention will improve use situation essentially. However, in the automatic garbage can also involve inclusion values since according to essays the team also considered how elderly and visually impaired people may benefit of automatic lid opening system as well as the warning signal when litterbag is almost full. In sum, the initial and final solutions were mentioned in writings and were embodied in solutions of the prototypes. 

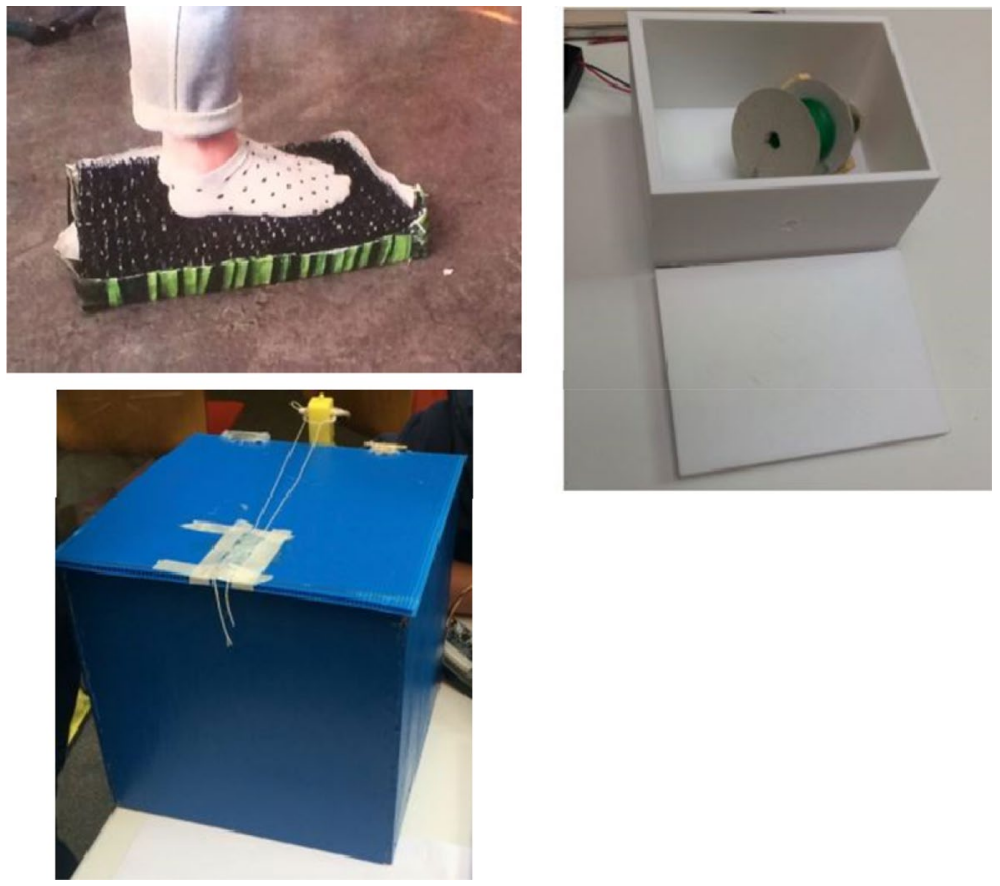

Fig. 2 Cleanliness co-inventions from left up Vacuuming carpet, Power supply box and bottom Automatic garbage can

\section{Reminder co-inventions}

Three co-inventions focused on organizing daily activities, such as reminding family members of their daily or weekly duties or reminding them to take their bus card or keys with them when leaving home (Fig. 3). These inventions varied from an ordinary Key rack that was intended to keep keys in one place with color-coded hooks for each family member. In the second period, two small containers were added to both sides so that other items could also be stored. The Smartboard reminded to do housework or other necessary things. It was a square-shaped board mounted on a wall, and when a family member passed it, a voice was activated to remind the person to do certain household duties. The device was designed to be programmed and reset by the users when the tasks were completed. The device was made of a plastic shell with a microprocessor (GoGo board) installed in it and the sensors hanging outside. Similarly, the pupils described Ectro-Alarm key and bus card locker - to help family members to remember to pick up keys and bus cards, but other items could also be kept there. The Ectro device gave an alert when family members walked past and reminded them to put or take keys or bus card when he or she leaves from home.

These co-inventions were based on the user value so that they also underlined inclusion and health inequality. Pupils mentioned in their essays special users or user groups such as impaired people, person that has specific problems in remembering, or need for personalization of the artefact. For example, in Ectro the team decided to develop different versions for visually impaired and deft people. Key rack team emphasized that when the product is 

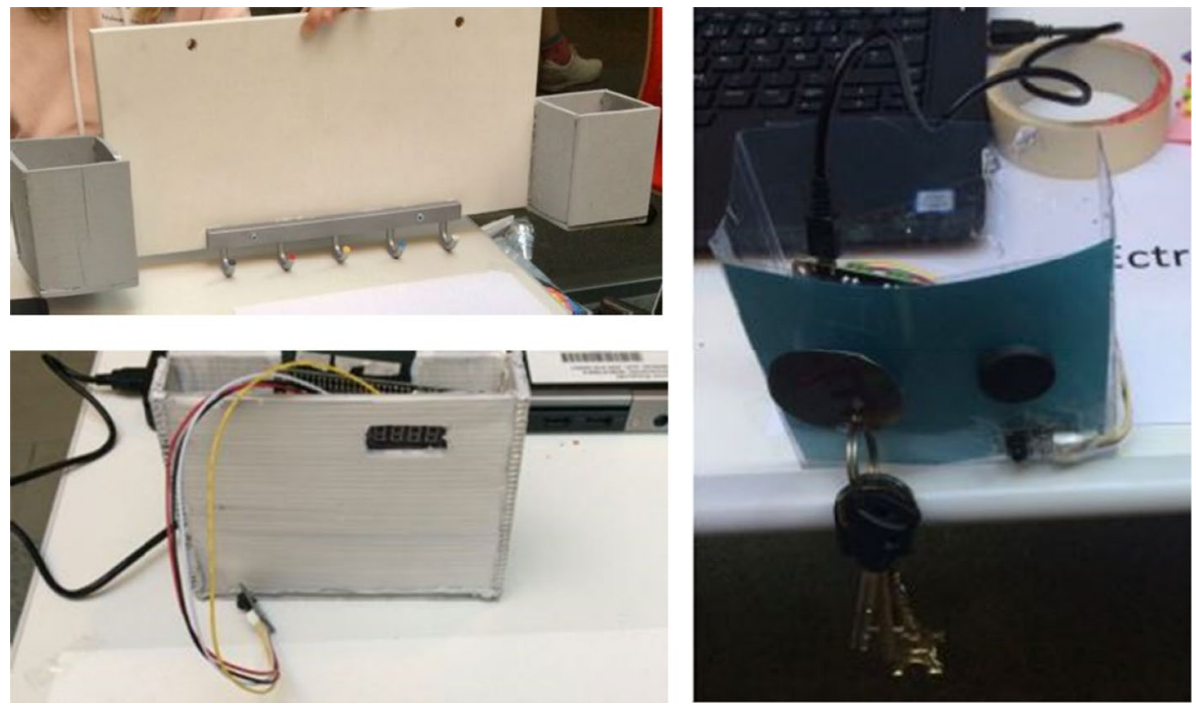

Fig. 3 Reminder co-inventions from left Key Rack and Smartboard and, on the right, Ectro: Alarm key and bus card locker

ordered from the Internet, users can make personalized choices when selecting base, hooks or decorations, and so forth. These values were said in the text but not found directly in the embodied artefacts.

\section{Well-being co-inventions}

Total of five inventions considered well-being themes. Three of them focused on hygiene functions (Fig. 4). Gel comb was designed so that the gel comes directly to the hair and user's hands will not get dirty. Their plan was to make it from wood or plastic and combs. It was designed to look like a regular comb with a tank inside. The invention was aimed at boys to speed up brushing hair. It worked by pressing the button and brushing at the same time. In spring 2017, the team made several prototypes and tried to get the gel out of the comb without success.

Similarly, Toothpaste in a pump bottle was based on the idea that the toothpaste can be pumped on the toothbrush easily without a mess. The team had pondered the idea through the entire project, and in the second period, they concentrated on testing how the toothpaste can get smoothly out of the bottle. Flying toilet seat was intended for all people that needed to use toilet immediately and were too tired to go to the bathroom. It was motivated by the team members' experiences of having difficulties finding a toilet when taking part in outdoor sports. The basic idea was that toilet seat flies to a person when he or she needs to use toilet. The team identified a genuine need but could not come up with any workable solution. The idea was presented in 2016, but the team gave up the idea in 2017. Besides, they were not able to produce a prototype, and according the collected data, the idea was never experimented or tested. The flying toilet seat was changed to the wake-up phone, but that invention was never explicated or constructed.

Two of the well-being co-inventions focused on healthy nutrition. Automatic snack machine was like a food-vending machine with the box with the machine inside. The 


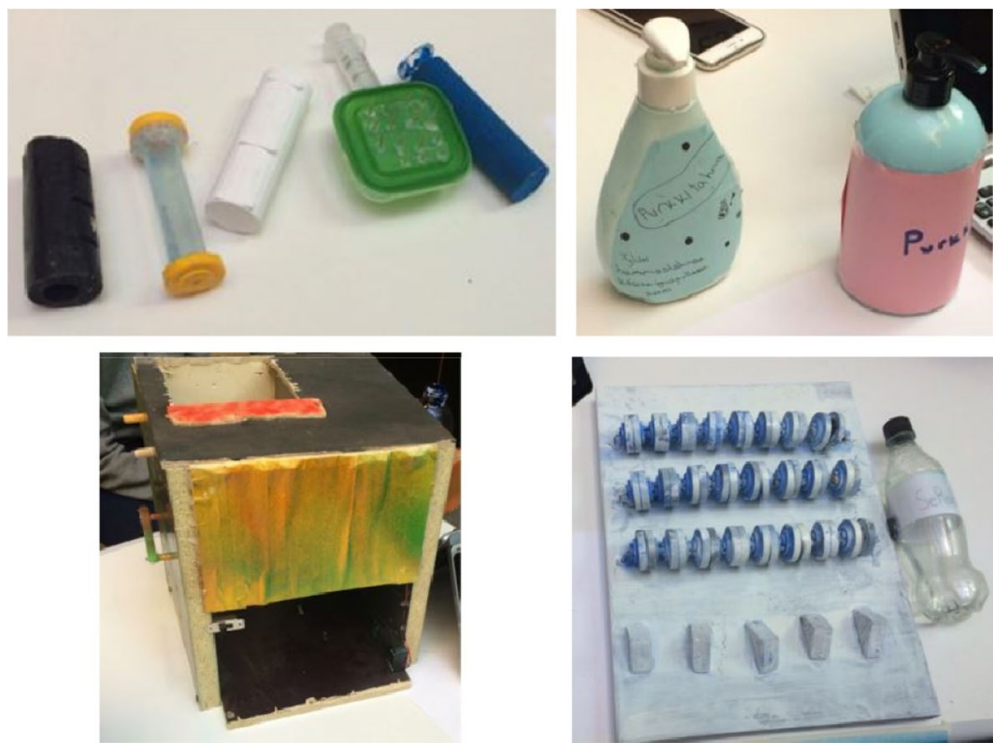

Fig. 4 From left up: Gel comb, Toothpaste in pump bottle, Automatic snack machine and SERAKU

device was used for rapid snacks and drinks. The appliance operated with a Lego robotics with a programmed motor, so that pressing a button makes the sandwich drop onto a plate. The system for providing a drink was made using the siphon principle. In the spring of 2017, the team built a smaller version of the device, intending to combine a fan to keep food fresh. Ice cream smoothie was intended to be a good and tasty, dessert-like drink that was made with ice cream, fruit, sugar, milk and chocolate. In spring 2017, the composition of the drink was tested, the package was designed, and the drink's nutritional content was indicated. The third well-being co-invention was related to exercises and sports. SERAKU's name came from the Finnish words for back crunching exercise equipment that could be used for sports, scratching and massage at the same time. It operated without electricity with the user's own power. In the second period, a rack for a beverage bottle was added to a side (see Fig. 4).

These co-inventions were also based on the user value but not referred to the inclusion or healthy inequality. The user was specified, such as boys or athlete. Also, some ideas about personalization were proposed, for example, different kind of sandwiches or different toolsets in SERAKU. The toothpaste in pump bottle invention also underlined environmental values because the team pondered the waste of plastic tubes, and caps.

In one set of team members' essays, Spy-briefcase was quite nebulously explained. The team had hard to create a shared understanding and concentrate only some main functions of the briefcase. In the essays, the team describes that the briefcase was like a cardboard box, and it was intended to prevent bullying. In the journal notes of spring 2017, the function of the briefcase was defined as spying on suspicious people and thieves. Thus, the briefcase had a hole through which the phone can video record what is going on around. The functions of the spy briefcase were trimmed so that it was only designed to take photographs. Improvements of this co-invention were mainly related to the strengthening of the handle, painting the briefcase and pondering how one can record video from the inside of the briefcase. 
To conclude, the analysis of team members' descriptions revealed that the details of their innovations varied a lot, especially in the essays written in the middle of the project periods. During the second project period at spring 2017, the inventions were further developed: in most of cases the basic function or appearance did not change, whereas in some cases the construction had radically changed after in-depth exploration and testing of the co-invention. Some very original ideas for known problems were found, for example, vacuuming carpet and gel comb for styling hair, even though these teams were not able to construct fully functional solutions: the gel comb team had a hard time figuring out how to get the gel out of the container. Similar way, vacuuming carpet team explained that it was challenging to design and test the idea because of "lack of electricity"-they were not able to test their vacuuming "motor", and thus the idea was changed more feasible solution. In one case the co-invention based on the idea of putting it into other use contexts: a regular soap-pump bottle was put to another use so that it contained toothpaste, and the toothpaste was pumped onto the toothbrush easily. Furthermore, at the beginning of the project, user or use-value of the products were emphasized, but also some environmental values and health inequalities were also raised up.

\section{Progress of the co-invention process}

The co-invention project followed a teacher-planned schematic structure, but during the project, each team progressed according to their own requirements. The progress of the invention process was analyzed from the pupils' essays, using in following categories: (1) refining design context, constraints and creating design ideas, (2) evaluating design ideas and constraints, (3) experimenting and testing ideas or the prototype. These phases were easily recognizable from the essays.

The refining design context started by a reflection on various everyday challenges. The first task was to think about various everyday challenges at home together with the parents. At school, they continued by brainstorming the ideas from home in randomly selected groups in which they also proposed their own challenges and design ideas. Then pupils grouped the ideas and defined users, needs, and functions, and finally selected one idea or combination of multiple ideas to further processing. This home-school phase came clearly out in large part of the writings, and some teams selected their everyday challenges from home or family. However, for one invention - toothpaste bottle - the idea has been hatched for several years, and with the invention project, there opened a channel to move toward the **realization of the design idea.

Two or three years ago I was visiting grandmother, and I thought that toothpaste in

a jug would be a really good idea. This idea lurked in my mind until that day, the Co4Lab-project started. I finally got the idea out (S2)

During the brainstorming session, teams were encouraged to propose a wide range of creative ideas without being too critical. Thus, at the beginning of the co-invention process, several creative design ideas were generated, from which the teams were able to choose those for further development. Each team had several ideas that they mentioned in their essays; there were many examples of their ideas, such as a sensor that recognizes dogs or a machine that eradicates weeds. Some of the ideas created in brainstorming sessions were described as odd or impossible: 
When we started Co4Lab [the name of the project] designing inventions and ideas, we turned around millions of crazy ideas, but that's the purpose of the brainstorming. Our first ideas were, for example, a type of phone charger and car without steering wheel.... (S16)

While generating creative design ideas, pupils also addressed various design constraints. They considered, in some cases, what would be easy to make and what would be the most practical co-invention. Pupils worried about the time limits, functionality of the invention or pondered difficulties in implementation. In dealing with time constraints, pupils emphasized, for example, "while selecting the invention, we considered how much time we had and what kind of material was available" (S16). The expected difficulties in implementing their co-invention led to reflections on how the co-invention might be constructed. Consideration of the functionality of the co-invention appeared several times in the writings. Pupils were wondering whether the co-invention made sense and whether it would be practical.

At the beginning of the design, we took into account that the invention should be nice and practical. (S40)

At first, we took into account what we were most likely to accomplish, what would be really useful, and what would be most interesting to do as well. (S9)

The various ideas from home were categorized and critically evaluated in teams at school, and teams were encouraged to select their key invention. In order to narrow down and evaluate teams' initial ideas, the teams used differing methods. In some teams, everyone in the group chose one of his/her own ideas, and then they voted on a single idea for further development. In other teams, members negotiated for a while on each team member's ideas for co-invention and then chose those that could be easily carried out. Thus, when evaluating and making the selection, the pupils focused on the realization of the idea and level of difficulty. Particularly, qualifying the idea of coinvention was influenced by whether the idea was easy or difficult to implement. This can be seen as a practical constraint as it refers to the realities associated with the construction of the co-invention.

We started to think about what challenges we are doing and what kind of an invention should be made to solve the problem. We chose the three problems in which we had invented and took the first idea under the work. We chose the inventions so that each of us had one of the inventions and we wonder what we can realize (implement) and what we cannot. We chose those which can easily implement. (S34)

While evaluating ideas, the pupils, at the same time, also highlighted the constraints related to the co-invention.

We wondered how the idea could be realized, is it possible to implement it? For example, would a thick paste flow through the thin tube of a liquid soap bottle? (S2)

In the essay instructions, the pupils were asked to describe how ideas developed. However, most often, in this context, pupils only mentioned that ideas developed, for example, by thinking through. Some pupils also wondered what new things could be included in the invention, and different new developmental ideas were raised.

First, the appearance and composition were considered. Then the materials and implementation were considered. The plan always got new ideas. (S13) 
There were much fewer notions about the experimenting and testing ideas, whereas construction of prototypes and implementation of co-invention were considered both difficult and easy. Pupils described how they tested the functionality of prototype: Sometimes, they needed to change or replace materials and, in general, the technical implementation was considered challenging. The functionality of the prototype was only mentioned when it did not act as expected or if it broke.

The most difficult part was the implementation of the invention. Sometimes it has gone well, but there have been hardships, for example, with materials and implementation. However, we made a few compromises and got the invention finished. (S16)

The hardest part of the project was to make the prototype as it always breaks down and we had to invent another way to fix it. (S40)

To conclude, the essays provided information from pupils' perspective of how creative ideas were generated; that is one of the most important phases of creative problem-solving in design and technology context. Pupils ability to recall their iterative ideating process even after a long time illustrate its importance to their progress. Furthermore, the evaluation of ideas and critical thinking are also crucial for improving and selecting promising ideas for further development. Thus, critical thinking was important while considering different constraints related to design and helped pupils to focus their attention on the possibilities to implement the co-invention. It appeared to be important for them to be able to solve the challenge in a practical way and efficiently within time limits.

\section{Quality of collaboration}

The class in the present study represented inclusive class, and there were several pupils that had various learning difficulties. The co-invention project was intended to provide diverse pupils a sense of contribution, that is, they experience that they are doing something worthwhile together, each pupil's unique efforts and accomplishments matter, and that the whole team is jointly reaching something that no one could have done on his or her own. The co-invention teams were formed based on pupils' own choice, and they had collaborated earlier. For example, Gel comb team consists of two mainstream and three LD pupils and all were boys, whereas Key rack team consists of two mainstream and one LD pupils, and all were girls. Thus, the research question how pupils described their team collaboration and what major difficulties they encountered were crucial.

In the essays, the pupils described how their collaboration was functioning. The pupils described their collaboration during the project generally as very good and all members participated in the activities. Almost all of the pupils $(\mathrm{N}=40)$ spoke about the team as "us" even though they wrote essays individually. The internal reciprocity of the team was seen in pupils' active participation and division of labor as well as consideration and communication with others. The smooth running of the collaboration was dependent on everyone taking equal part in the work. The teams worked mainly at the school together, but two teams mentioned that they had used technology (Skype, Snapchat) so that a missing group member could participate in the joint process.

In some essays, teamwork was seen, upon reflection, as a process that began poorly but improved towards the end. It was also described to the contrary; i.e., the co-invention process started well but deteriorated and became challenging toward end. Key rack team reported that they had time to time some conflicts, but they ended up with a positive solution. This was also verified from the video recordings. In particular, the Power 
box team felt that collaboration did not take place. Challenges were in the communication, and team spirit was considered weak. According to three team members, however, the collaboration progressed smoothly at first, but they also experienced difficulties. They have difficulties deciding together how and who will take responsibility for specific tasks: two boys walked around between other groups.

Our collaboration went really well and really badly. In the beginning, when we came up with the idea what we started to do was fine, but when we started to make a power box, we started arguing how the invention would be built and who would do what. (S19)

First time it went really well, but in the next few days, we did not work very well as a group. The last few times I had to take action, so even though some of our group felt that they would not like to make the invention, me and the other two, we started doing it as well as we could. (S23)

Some pupils emphasized the importance of the division of labor meaning that everyone had an own area of which he or she was responsible for. For instance, inside of the Gel Comb team, pupils formed three work pairs: one LD pupil helped one mainstream pupil to organize the group's tasks: When everyone knew what to do, they worked together on different areas based on whatever needed to be done that is constructing prototype or drawing sketches. In general, challenges in the division of labor emerged, especially in the construction and implementation phase of the co-invention. The pupils in the Ectro team felt that the collaboration was good as the work continued in the same way, although some of the group members were not present at every meeting.

Our collaboration has gone well and there has not been much disagreement. Sometimes, if someone was sick or absent for some other reason, others did the job for his absence. So, I could say that our collaboration went very well! (S16)

Personal responsibility included identifying which group member needs help, support, and encouragement. Particularly in the design journals, pupils' needs for support emerged. However, few teams had difficulties in developing their co-invention. Especially constructing the prototype was challenging, because they encountered many problems with technology, and neither the support nor assistance from the teacher was always available. The writings revealed that the pupils felt that a working session was lost when there was no guidance or support for a particular thing and without it, it was impossible to make the co-invention forward.

Pupils' collaboration skills developed during the 2 years. Especially in the design journey entries, the division of the labor became more apparent than in the essays. In the design journal entries from 2017, the pupils described more clearly their team's division of labor. Some of the team members were assigned to help others in general or to help a particular group member. The group processing involved reflections on how well goals have been achieved, who helps the team to work and what kind of behavior is needed to overcome. In many teams, excessive chatting and the fact that not everyone was focused on the project was considered a problem. Often, a pre-planned division of labor helped to advance the shared work. Even the pupils emphasized the division of labor so that it was evident that, for example, the Gel comb team had a recognizable leader who took responsibility to organize team members' work -this became evident from the video, and it was also confirmed all members in the interviews. 
In the Key rack team, however, three girls formed a group, in which they had shared responsibility for their group tasks. In the interview data, one LD pupil described how they, at the beginning of the session, all discussed how to proceed, and then they divided the tasks. When the invention had to be altered somehow, it was decided democratically: everyone's ideas were discussed, written down to diary, and finally voted. She and other team members also pointed out that their teamwork did not work out without conflicts: at the beginning of the co-invention project, they had difficulties in making compromises or accepting others' opinions related to design ideas or solutions. All of the girls told that in order to make decisions, they voted or asked teacher's help. These situations were also notified from the video-recordings. The conflicts were between mainstream girls, whereas LD pupil tried to negotiate and find compromise. The teacher's role was not emphasized in essays but based on the video-recordings, she was very much needed in the early phase of the project to help Key rack team to solve disagreements and make the decisions about the product to be designed. In general, all the LD pupils felt that collaborative learning was easier for them because of the shared responsibilities involved and the capability of utilizing each member's strengths.

\section{Discussion and implementations}

Our aim was to describe and analyze the overall process of the elementary school pupils' co-invention project as well as examine the resulting co-inventions. Our emphasis was especially on what students thought and remembered about the project. The main research data was based on the pupils' structured essays on their reflection of design process and their design journal entries; we also looked at the video and interview data in order to validate and cross-reference our data analysis. Pupils' essays were used as the main data because we wanted to examine whether young pupils are able to reflect on their design processes, and identify various stages of the co-invention process and learn to improve their solutions. Moreover, based on these reflections, we could better evaluate what are the major difficulties pupils encountered and what things are learned more easily in an openended co-invention process?

The open-ended design challenge resulted in a wide variety of co-inventions, some of them not feasible. The analysis suggested that the co-invention process involved creative (generating ideas, refining solutions toward more detailed level) and critical thinking by evaluating ideas, defining constraints and testing the prototypes. All teams recognized the importance of ideation and brainstorming in inventing, and they described various ideas or problematic situation where they started from. They also clearly recognized external constraint related to designing (resources, time and money). Furthermore, the teams also reported the constructing and prototyping phases of the co-invention project. The implementation of an invention ideas with testing the prototype was considered crucial. The pupil teams' co-inventions were categorized according to their main function, such as improving cleanliness, providing reminders or addressing hygiene, health and nutrition issues. The pupil inventions also reflected issues related to user values (health-related inequality, inclusion or personalization), use values (helping to resolve problematic situations) and environmental values. These kind of underlying values and motivations were not very strongly emphasized in the essays or journal entries. Anyhow, the long-term, open-ended invention project provided valuable learning opportunities for iterative problem solving, shared meaning making and team working that requires, division of labor, organizing 
process and personal responsibility. It also provided-according to LD pupils interviewssense of contribution that they are doing something worthwhile together. Although the collaboration was not always smooth, in the essays most of the pupils concluded that the project was fun and they were proud of their achievements. This was also apparent from the presentations in the Invention Fair when teams were presenting their co-inventions to wider audience.

In this study, the aim was not to determine the creative value of the pupils' co-inventions but to examine the innovations generated in order to understand better the ways of scaffolding pupils' capabilities of learning to use knowledge in coping with complex, openended problems. That is to say; we considered all outcomes as creative in the elementary school context. An innovative idea needs to be functional and appropriate for the purpose, and most of the teams' co-inventions were considered appropriate and promising. Only two co-inventions (e.g. Spy-briefcase and Flying toilet seat) were not explicated clearly enough and can be considered as quasi-creative (Cropley and Cropley 2010) since they lacked feasibility, i.e., potentials of being implemented in reality.

In the present study, the proposed innovations can be divided according to analogical (i.e., mechanical construction) and digital co-inventions. Most of the co-inventions were based on analogical construction, and only three final innovations used digital sensors; nevertheless, the design task presupposed that inventions integrate material and digital elements. Some of the co-inventions were based on an already existing idea or product that was used in another context; for example the pump bottle was planned to be extended for helping to wash teeth. In some cases, the pupils' co-inventions were based on the adaptation of existing artifact designs in terms of slightly modifying an existing product, for example, Key rack and Automatic garbage can. According to Howard et al. (2008), this is typical for an invention process: pupils design and combine ideas and knowledge they already know for creating something new. However, more deeper multi-modal analysis of pupils' teams design concepts and solutions for material artefacts from pupils' interviews could have provide much more detailed descriptions of the underlining values and motives of their various design decisions (Derboven et al. 2015).

Considering the class composition, the LD students' participation did not appear in the data, and they were able to participate without any additional adaptations. Some teams had difficulties in constructing their prototype because they encountered technological problems both in terms of using unfamiliar digital fabrication tools and finding feasible ways of implementing their ideas with available traditional and digital tools. Key rack team proposed to use sensor for recognition but gave up that idea because they considered GoGo board too difficult; also gel comb team would have needed more support with testing pneumatic. Because of the complexity of problems addressed the support and assistance from the teachers, who themselves were not familiar with all tools used by pupils, was not experienced to be enough. There was also researcher present who was familiar with technologies utilized but her assistance was not mentioned by pupils in the essays; she was more actively helping with technology in the second period.

During the project, the pupils visited two museums (Technology museum and Design museum), a professional designer and an inventor also visited at the school. Nevertheless, the pupils did not mention these visits in their essays or reflected on the expert knowledge provided. In other words, they either did not remember the visits in museums or did not make a connection with associated expert knowledge and the project. Thus, when planning these kinds of project, it is important that teachers assist pupils in making sense and seeing the relevance of expert knowledge and explicitly support its' integration and application across the co-invention process. A more direct connection to 
techno-scientific principles, such as pneumatic, could have benefited pupils' co-invention efforts. Thus, technological or science principles were not enough highlighted in the co-design process. Some teams (e.g., vacuum carpet) changed their intended technological implementation after preliminary testing of the invention prototype. However, every team did not manage to proceed in applying science and technology principles. For example, Flying toilet seat team did not manage to move from their silly first idea of solving the design challenge to co-invention with plausible scientific and technological principles. To conclude, pupils would have needed more guidance and scaffolding for transiting from silly ideas to makeable inventions with applied sciences. In technology invention projects, pupils had to be deliberately supported in considering the technological and scientific functioning of the co-inventions. The process of recognizing various constraints and generating ideas of implementing the invention with quick mock-ups and rapid prototypes should be more strongly fostered.

The analysis revealed that some pupil teams could have benefited from more direct teacher guidance supporting the creation of feasible solutions. The teachers did not constrain the pupils' design ideas but provided some instructions for further selection of coinvention: For example, they asked pupils to ponder pros and cons of these inventions. They followed teams' designing and provided materials but did not much interrupted or guided pupils' designing. The teachers could have supported design process more actively reminding different phases of the process (i.e., process models), reflect on these models in general whole class discussion and also by giving short demonstrations of techno-specific principles (Davis and Miyake 2004; Koski et al. 2011; Viilo et al. 2011). Although the process of team collaboration was in general considered successful, the teachers should, moreover, emphasize the importance of the flexible division of labor so that everyone has his or her own areas of responsibility complementing those of the others. Co-inventing does not mean leaving children alone: the role of the teacher is to help succeed, to create the prerequisites for working skills and skills for building a prototype. The teachers could have guided, for example, the Flying toilet -team to recognize that it is very hard to find a feasible solution and try to guide them to change the challenge or the problem. Also, teachers could have organized time to time sessions where pupil teams could have brought their ongoing problems under joint discussion and let peers to propose solutions. More intensive technical support could have fostered the advancement of teams' working. However, in this project, teachers did not have enough experiences of craft and technology education. They might have considered that providing pupil teams many degrees of freedom suits this kind of pedagogy.

The present investigation was one of our first efforts of bringing elements of maker culture to schools. Although we have been working with pedagogies of knowledge-creating learning, including artefact design, for more than a decade, this was our first effort to utilize digital fabrication technologies at such projects. In this open-ended co-invention project, pupils were able to practice and learn a wide variety of things from designing to collaboration and specially to engaging to long-term working without structured and detailed lesson plan. However, the lesson learned in this project was that teacher guidance plays a central role in the successful pursuit of co-invention processes. In our subsequent iterations of similar design experiments, we have proactively taken this lesson into consideration (Tenhovirta et al. in review, submitted). Moreover, we have cultivated peer-tutoring pedagogies for providing more intensive support and guidance for pupils' co-invention teams. In one of our studies, we first trained 8th grade pupils to use digital tools needed for the design and invention processes and invited them to provide peer tutoring to their 7 th grade peers with good results (Tenhovirta et al. in review, submitted). 
A limitation of the study is related to the method of data collection. The present study mainly relied on the pupils' written essays and teams' design journal entries and thus represents pupils' recollection of the co-invention processes; such reports do not necessarily reflect what was happening in the classroom in more depth. Thus, for example, the essays did not provide rich or detailed information on prototyping building and decisions made by then; only the difficulties related to construction prototypes were mentioned. One advantage of the essays was that were able to include all design teams in our analysis, which would have been hard with observation. Furthermore, we also collected video data of three teams' work during the entire project and their interviews. Thus we have been able to compare pupils' structured essays and design-folder notes with the videos of the teamwork: the pupils appear to have reported very honestly what was going on during the designing, and we believe that our interpretation of the co-invention process appears to be quite reliable.

Acknowledgements Open access funding provided by University of Helsinki including Helsinki University Central Hospital. Funding was provided by Academy of Finland (Grant No. 286837).

Open Access This article is licensed under a Creative Commons Attribution 4.0 International License, which permits use, sharing, adaptation, distribution and reproduction in any medium or format, as long as you give appropriate credit to the original author(s) and the source, provide a link to the Creative Commons licence, and indicate if changes were made. The images or other third party material in this article are included in the article's Creative Commons licence, unless indicated otherwise in a credit line to the material. If material is not included in the article's Creative Commons licence and your intended use is not permitted by statutory regulation or exceeds the permitted use, you will need to obtain permission directly from the copyright holder. To view a copy of this licence, visit http://creativecommons.org/licenses/by/4.0/.

\section{References}

Alper, M. (2013). Making space in the makerspace: Building a mixed-ability maker culture. In Interaction Design and Children Conference, June 24-27, 2013, New York, NY, USA.

Barlex, D. (2007). Assessing Capability in Design and Technology: The case for minimally invasive approach. Design and Technology Education: An International Journal, 12(2), 49-56.

Bereiter, C., \& Scardamalia, M. (1993). Surpassing ourselves: An inquiry into the nature and implications of expertise. Chigago, IL: Open Court.

Blikstein, P. (2013). Digital fabrication and making in education: The democratization of invention. In J. Walter-Herrmann \& C. Büching (Eds.), FabLab. Of machines, makers, and inventors (pp. 203-222). Bielefeld: Transcript.

Chi, M. T. H. (1997). Quantifying qualitative analyses of verbal data: A practical guide'. Journal of the Learning Sciences, 6, 271-315.

Clapp, E. P., Ross, J., Ryan, J. O., \& Tishman, S. (2016). Maker-Centered Learning: Empowering young people to shape their worlds. San Francisco, CA: Jossey-Bass.

Cropley, D., \& Cropley, A. (2010). Recognizing and fostering creativity in technology and design education. International Journal of Technology and Design Journal, 20, 345-358.

Davis, M., Hawley, P., McMullan, B., \& Spilka, G. (1997). Design as a catalyst for learning. Alexandria, VA: Association for Supervision and Curriculum Development.

Davis, E. A., \& Miyake, N. (2004). Explorations of scaffolding in complex classroom systems. The Journal of the Learning Sciences, 13(3), 265-272.

Denson, C., Buelin, J., Lammi, M., \& D’Amico, S. (2015). Developing instrumentation for assessing creativity in engineering design. Journal of Technology Education, 27(1), 23-40.

Derboven, J., Van Mechelen, M., \& Slegers, K. (2015). Multimodal analysis in participatory design with children: A primary school case study. In CHI 2015, April 18-23, 2015, Seoul, Republic of Korea.

Finnish Basic Education Act 642. (2010). Retrieved July 5, 2018 https://www.finlex.fi/en/laki/kaannokset /1998/en19980628.pdf.

Finnish National Agency of Education. (2016). National core curriculum for basic education 2014 (2nd ed.). Helsinki: Juvenes Print-Suomen yliopistopaino Oy. 
Gero, J. S., \& Kannengiesser, U. (2004). The function-behaviour-structure framework. Design Studies, 25, 373-391.

Hennessy, S., \& Murphy, P. (1999). The potential for collaborative problem solving in design and technology. International Journal of Technology and Design Education, 9(1), 1-36.

Honey, M., \& Kanter, D. (2013). Introduction. In M. Honey \& D. Kanter (Eds.), Design, make, play. Growing the next generation of science innovators (pp. 1-6). New York: Routledge.

Howard, T. J., Culley, S. J., \& Dekoninck, E. (2008). Describing the creative design process by the integration of engineering design and cognitive psychology literature. Design Studies, 29, 160-180.

Kafai, Y. (2006). Constructionism. In R. K. Sawyer (Ed.), The Cambridge handbook of the learning sciences (pp. 35-46). New York: Cambridge University Press.

Kafai, J., Peppler, K., \& Chapman, R. (Eds.). (2009). The computer clubhouse: Constructionism and creativity in youth communities. New York: Teachers' College Press.

Kangas, K., Seitamaa-Hakkarainen, P., \& Hakkarainen K. (2013). Design thinking in elementary students' collaborative Lamp designing process. Design and Technology: an International Journal, 18(1), $30-43$.

Koski, R. Klapwijk, \& de Vries, M. (2011). Connecting Domains in Concept-Context Learning: A model to analyse education situations. Design and Technology Education: An International Journal, 16(3), $50-61$.

Martinez, S. L., \& Stager, G. S. (2013). Invent to learn: Making, tinkering, and engineering in the classroom. Torrance, CA: Constructing Modern Knowledge Press.

Niilo Mäki Instituutti. (2015). Clinic for learning difficulties. Retrieved June 9, 2015 http://www.nmi.fi/en/ lastentutkimusklinikka-en.

Papert, S. (1991). Situating constructionism. In S. Papert \& I. Harel (Eds.), Constructionism. Cambridge, MA: MIT Press.

Rutland, M., \& Barlex, D. (2008). Perspectives on pupil creativity in design and technology in the lower secondary curriculum in England. International Journal of Technology and Design Education, 18(2), $139-165$.

Seitamaa-Hakkarainen, P., \& Hakkarainen K. (2017). Learning by making. In Peppler (Ed.), The SAGE encyclopedia of out-of-school learning, pp. 421-424.

Seitamaa-Hakkarainen, P., Viilo M., \& Hakkarainen K. (2010). Learning by collaborative designing: Technology-enhanced knowledge practices. International Journal of Technology and Design Education, 2(2), 109-136.

Tenhovirta, S., Korhonen, T., Seitamaa-Hakkarainen, P., \& Hakkarainen, K. (in review). Peer tutors as student experts: Networked peer assistance for co-invention projects at a lower secondary school. In Mentoring \& Tutoring: Partnership in Learning.

Viilo M., Seitamaa-Hakkarainen, P., \& Hakkarainen K. (2011). Supporting the technology-enhanced collaborative inquiry and design project - A teacher's reflections on practices. Teachers and Teaching, Theory and Practice, 17(1), 51-72.

Yrjönsuuri, V., Kangas, K., Hakkarainen, K., \& Seitamaa-Hakkarainen, P. (2019). The roles of material prototyping in collaborative design process at an elementary school. Design and Technology Education: An International Journal, 24(2), 141-162.

Publisher's Note Springer Nature remains neutral with regard to jurisdictional claims in published maps and institutional affiliations. 